\title{
Tributo ao Professor José Luiz Meurer
}

Perhaps, what really matters is that whatever is written or whatever we write, whatever texts we read or analyse, whatever way we conduct ourselves, we never lose sight of our essence as human beings in search of a better self and a better world.

Meurer, 1998, p. 144.

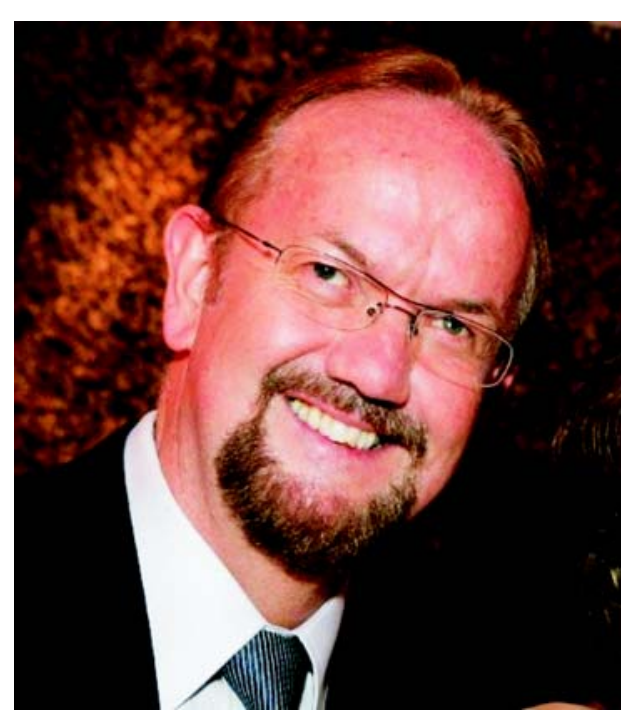

Amigos e colegas do Professor Dr. José Luiz Meurer prestam uma homenagem a ele em forma de uma entrevista póstuma. As respostas foram pinçadas de seus textos. Sabemos que o conhecimento é dinâmico e que, provavelmente, Meurer teria muito mais a dizer do que o que registrou em seus textos, mas, ao reunir fragmentos de seu pensamento, a intenção foi perpetuar sua memória, por meio de sua rica produção acadêmica.

Em todos nós ficou a saudade e a sensação de perda do amigo e do acadêmico exemplar.

Vera Menezes (organizadora)

Adail Sebastiāo Rodrigues-Júnior pergunta: Caro professor, qual é a relação entre texto e discurso, quais são as implicações dessa relação para o ensino de produção textual e que papel os gêneros textuais exercem nesse contexto de ensino?

\section{Professor José Luiz Meurer responde:}

Para estabelecer a diferença entre texto e discurso, sigo a perspectiva de Foucault (1972), Kress (1989) e Fairclough (1992). Para entendermos esses conceitos, podemos iniciar com a afirmação óbvia de que não vivemos como 
seres isolados. Como diz o poeta John Done, no man is an island - ninguém é uma ilha. Ao contrário, cada indivíduo é um agente social inserido em uma rede de relações sociais que acontecem em lugares específicos de agrupamentos socioculturais específicos (KRESS, 1989, p. 5). Em segundo lugar, é preciso lembrar que cada agrupamento social é controlado por um conjunto de instituições que, como diz Kress (p. 6), têm 'suas práticas, seus valores próprios, seus significados, suas demandas, suas proibições e suas permissões' (minha tradução). As práticas, os valores, os significados, as demandas, proibições e permissóes existentes entre os diferentes agrupamentos sociais, por sua vez, exercem influência direta sobre os indivíduos que convivem dentro desses grupos. Por último, as práticas, os valores e os significados dos grupos sociais são expressos e articulados em grande parte através da linguagem.

Tendo como pano de fundo as três observações do parágrafo anterior - isto é, que vivemos em ambientes institucionalmente organizados, que as instituições são caracterizadas por práticas e valores específicos e que tais valores são expressos através da linguagem - podemos definir discurso e texto da seguinte forma: o discurso é o conjunto de afirmações que, articuladas através da linguagem, expressam os valores e significados das diferentes instituiçôes; o texto é a realização linguística na qual se manifesta o discurso. Enquanto o texto é uma entidade física, a produção linguística de um ou mais indivíduos, o discurso é o conjunto de princípios, valores e significados 'por trás' do texto. Todo discurso é investido de ideologias, isto é, maneiras específicas de conceber a realidade. Além disso, todo discurso também é reflexo de uma certa hegemonia, isto é, exercício de poder e domínio de uns sobre os outros. A partir dessas características, o discurso organiza o texto e até mesmo estabelece como o texto poderá ser, quais tópicos, objetos ou processos serão abordados e de que maneira o texto deverá ser organizado (KRESS, 1989). Assim, por exemplo, serão muito diferentes os textos criados dentro do discurso da igreja, da escola, da indústria, da ciência, dos diferentes partidos políticos, da prostituição, etc. Cada instituição tem seus discursos, sempre investidos de determinadas ideologias, determinadas maneiras de ver, definir e lidar com a 'realidade'. Isso se reflete nos textos, através dos quais nos comunicamos e executamos ações sociais.

As diferentes línguas, por sua vez, funcionam como um potencial de opções e possibilidades de expressão e constituem a base a partir da qual os indivíduos criam os seus textos. $\mathrm{Na}$ verdade, os indivíduos constroem textos não através do uso da língua apenas, mas a partir da internalização de outros 
tipos de textos já existentes (BAKHTIN, 1992). Tudo o que alguém escreve tem um grau de intertextualidade, ou seja, é influenciado por - e depende de - textos que ocorreram anteriormente (BAKHTIN, 1992; FAIRCLOUGH, 1992). A importância desse fato para a produção de textos é que o potencial de opções oferecidas pela língua e, mais especificamente, pelos diferentes gêneros de textos existentes, não pode ser usado livremente. Ao contrário, sempre que alguém escreve, há uma expectativa de que o texto produzido seja o reflexo de determinados discursos e que, portanto, espelhe as maneiras de falar ou escrever das diferentes instituiçóes que regulam a comunidade onde o indivíduo está inserido. Por isso, há também uma expectativa de que todos os textos tenham formas, funções e conteúdos específicos. E é esta expectativa que impõe ao escritor um conjunto de exigências de caráter psicossociolinguístico que precisam ser contempladas durante o processo de composição.

Os gêneros textuais - tanto em termos de quais gêneros serão escolhidos e de como serão usados - têm estreita relação com a noção de hegemonia (FAIRCLOUGH, 2001, p. 29). Por quê? Porque a escolha de textos e o seu modo de uso dependem frenquentemente das formas de dominação estabelecidas, i.e., de quem possui mais, ou menos, poder em determinadas circunstâncias. Pensemos, por exemplo, nos textos usados nas escolas. Quais são eles, quem os escolhe ou determina? Não são apenas os professores (principalmente) e alunos, mas também determinações que vêm de práticas discursivas mais amplas, pertencentes ao discurso que engloba, por exemplo, o programa da escola, as normas da secretaria, da prefeitura, ou do estado, os PCN, ou o MEC. A escolha de textos pode envolver ainda pressões da sociedade; por exemplo, usar ou não usar textos que tratem de drogas, de relacionamento ou identidade sexual etc. Fairclough (1989) fala em poder no discurso e poder por trás do discurso. O primeiro é mais visível e pode ser exercido in presentia, explicitamente, através de palavras ou textos específicos. O poder por trás do discurso deriva de ordens do discurso não tão visíveis, como é o caso dos discursos por trás da escolha do livro que a escola vai adotar ou dos discursos que determinam o que significa ser professor e consequentes formas de comportamento ou posicionamento diante da profissão. São os poderes por trás do discurso que determinam qual gênero é mais apropriado para determinadas situações.

Isto não significa que as práticas discursivas não possam ser alteradas. Conforme aponta Giddens - e Fairclough adota a mesma perspectiva -, cada situação de prática social é simultaneamente coercitiva ou coibidora e 
capacitadora. Isto quer dizer que ao mesmo tempo em que uma prática social pode repetir ou reforçar práticas anteriores, pode também questionar, desafiar e mudar práticas anteriores. Portanto, ao mesmo tempo em que os aspectos coercitivos ou coibidores em princípio promovem a repetição, os aspectos capacitadores permitem a mudança. Ter conhecimento sobre o envolvimento da linguagem nas questôes de poder pode cooperar para mudanças no exercício de formas de poder."

\section{Referências}

MEURER, J. L. Esboço de um modelo de produção de textos. In: MEURER, J. L.; MOTTA-ROTH, D. (Org.). Parâmetros de textualização. Santa Maria: Ed. Da UFSM, 1997. p. 13-28.

MEURER, J. L. Gêneros textuais na análise crítica de Fairclough. In: MEURER, J. L.; BONINI, A.; MOTTA-ROTH, D. (Org.). Gêneros: teorias, métodos, debates. São Paulo: Parábola Editorial, 2005. p. 81-106.

Orlando Vian-Jr pergunta: Caro Professor Meurer, muito se fala na relação entre texto e contexto, mas poucas são as propostas de análise dessa inter-relação. Outro ponto é: que teoria utilizar para se proceder a tal análise. Em sua opinião, em que medida o contexto onde um texto é produzido deve ser levado em consideração na análise não apenas de gêneros textuais, mas da linguagem e seu uso como prática social? Quais teorias o senhor adota para tais análises?

\section{Professor José Luiz Meurer responde:}

"Apesar do crescente grau de consenso sobre a relevância da inclusão do contexto na análise de gêneros textuais e no uso da linguagem em geral, temos ainda muito trabalho a realizar no que diz respeito tanto a maiores especificações de ordem teórica como à implementação de métodos de análise que dêem conta da inter-relação dos gêneros com o contexto onde ocorrem - em especial o contexto social mais amplo. ${ }^{1}$ Como é que efetivamente se analisa tal interrelação? Como podemos mostrar que um texto é influenciado ou determinado pelo contexto ao mesmo tempo que influencia e determina o contexto?

${ }^{1}$ Observe-se que essa não é uma preocupação recente na área da lingüística. Conforme aponta Halliday (1989), Firth, por exemplo - o primeiro professor de lingüística da Universidade de Londres - se debruçava sobre a questão nos anos 1950, apoiando-se em trabalhos do antropólogo Malinowski, nos anos 1930. 
[...] A noção de contexto que utilizo deriva parcialmente da lingüística sistêmico-funcional (LSF) e da teoria da estruturação. Da LSF - de base australiana (e.g., HALLIDAY, 1978; HASAN, 1978; KRESS, 1988; BUTT et al., 2001; EGGINS, 2004; HALLIDAY; MATHIESSEN, 2004; van LEEUWEN 2005) - adoto a noção de estratificação, que concebe o contexto como se bifurcando em contexto de situação e em contexto de cultura. Da teoria da estruturação (GIDDENS, 1979, 1984), por sua vez, adoto a noção de que o fluxo da vida humana - e esse fluxo inclui o uso dos gêneros - se dá sempre como parte de (a) práticas sociais, que são executadas por (b) indivíduos atuando sob prescriçôes de papéis relativos a certa identidade, e sempre em alguma (c) estrutura social definida em termos de regras e recursos. ${ }^{2}$ Estas três dimensões sociais - práticas sociais, indivíduos agindo de acordo - ou não - com prescrições de diferentes papéis identitários e em estruturaçôes sociais existentes relacionados a regras e recursos - servem de base sociológica para a minha análise de aspectos de gêneros em sua interconexão com o contexto.

Considero possível a inserção destas três dimensões da teoria da estruturação no contexto de cultura, em sua conceituação no âmbito da LSF. Estou, portanto, trabalhando inter-disciplinarmente, unindo aspectos teóricos e metodológicos da área de estudos da linguagem (LSF) e da área da sociologia (teoria da estruturação). [...]

[...] Toda forma de semiotização - produção de significações materializada em um determinado gênero textual precisa também ser entendida em relação práticas sociais, prescrições de papéis e estruturas sociais em forma de regras e recursos. A busca por procedimentos de análise de gêneros textuais incorporando aspectos dessas dimensões da teoria da estruturação está apenas começando. Além dos passos iniciais que acabo de apresentar, podemos continuar a perseguir novos procedimentos para responder perguntas como: por que diferentes grupos sociais criam diferentes significações de eventos, objetos, indivíduos e de si próprios? O que essas significações têm a ver com as prescriçóes de papéis envolvidas? O que as significaçóes podem nos revelar sobre os grupos, comunidades ou indivíduos que as criam com relação a regras e recursos?

A compreensão mais abrangente de qualquer texto - na verdade, a compreensão de qualquer commodity - se baseia em mediações semióticas

\footnotetext{
${ }^{2}$ Marx dizia: os homens [e as mulheres] fazem a história, mas em contextos já dados.
} 
(COLAPIETRO, 1993, p. 71) e na instanciação de regras e recursos, por indivíduos, em práticas sociais específicas. Não obstante, descrever essas mediações e suas inter-relações com o contexto é uma tarefa de complexidade imensa. De qualquer forma, realizado sob tais perspectivas, o estudo de gêneros textuais implicará a ampliação da compreensão da interface sociocultural da linguagem. Buscaremos entender um pouco mais a estruturação da vida social feita de regras e recursos que impulsionam a própria criação do texto que, no eixo da estratificação acima referido, se mescla com a própria existência."

\section{Referência}

MEURER, J. L. Integrando estudos de gêneros textuais ao contexto de cultura. In: KARKOWSKI, A.M.; GAYDECZKA, B.; BRITO, K. S. (Org.). Gêneros textuais: reflexões e ensino. Rio de Janeiro: Lucerna. 2006.

Desirée Motta-Roth pergunta: A serviço de que o senhor coloca sua pesquisa? Que implicações para o mundo da vida o senhor consegue elaborar a partir do seu trabalho?

\section{Professor José Luiz Meurer responde:}

"[É] necessário elaborar respostas para a pergunta: como descrever e explicar os textos, evidenciando que neles e através deles os indivíduos produzem, reproduzem ou desafiam a realidade social na qual vivem e dentro da qual vão construindo sua própria narrativa pessoal?

$[\mathrm{P}]$ rocuro contribuir com uma possível direção para se lidar com estas questôes, tendo em mente uma análise que possa ser aplicada a qualquer gênero textual, isto é, tipo específico de texto de qualquer natureza, literário ou não, oral ou escrito, caracterizado e reconhecido por função específica e organização retórica mais ou menos típica, e pelo(s) contexto(s) onde é utilizado (...). A abordagem que utilizo apóia-se em grande parte na Análise Crítica do Discurso e, mais especificamente, na noção de que o discurso tem um poder construtivo tríplice: (1) produz e reproduz conhecimentos e crenças por meio de diferentes modos de representar a realidade; (2) estabelece relaçóes sociais; e (3) cria, reforça ou reconstitui identidades." (MEURER, 2003, p.18).

"Descrever e explicar gêneros textuais relativamente às representações, relações sociais e identidades neles embutidas poderá servir para evidenciar que, no discurso, e através dele, os indivíduos produzem, reproduzem, ou desafiam as estruturas e as práticas sociais onde se inserem. Uma abordagem crítica dessa 
natureza poderá ajudar a entender que representar o mundo de uma determinada maneira, construir e interpretar textos evidenciando determinadas relaçôes e identidades constituem formas de ideologia. E uma abordagem desta natureza poderá ajudar a perceber que 'a ideologia é mais efetiva quando sua ação é menos visível' (FAIRCLOUGH, 1989, p. 85), quando representações, relações e identidades são vistas como senso comum, naturais, inquestionáveis. Para Fairclough (ibid.), a ideologia perpassa nossas práticas discursivas e práticas sociais, e está implícita nas formas de ver, pensar, compreender, recriar ou desafiar e mudar maneiras de falar e agir. E, se alguém torna-se consciente de que um determinado aspecto do senso comum, daquilo que parece natural, sustenta desigualdades de poder em detrimento de si próprio/a, 'aquele aspecto deixa de ser senso comum e pode perder a potencialidade de sustentar desigualdades de poder, isto é, de funcionar ideologicamente' (Ibid., p. 85).” (MEURER, 2003, p. 28).

“"[Q] uestôes sociais e políticas chave têm um caráter parcialmente lingüístico-discursivo' (FAIRCLOUGH; WODAK, 1997, p. 271) e (...) o estudo de questōes lingüístico-discursivas com base na A[nálise] C[rítica do] Discurso pode, portanto, revelar aspectos importantes da vida social. Assim sendo, ao analisar textos criticamente não est[ou] interessad[o] apenas nos textos em si, mas em questôes sociais incluindo maneiras de representar a 'realidade', manifestação de identidades e relações de poder no mundo contemporâneo (MEURER, 2005, p. 81).

A ACD permite aos / as professores / as encorajar seus / suas alunos / as a observar que tipos de textos precedem e seguem o uso de um determinado gênero específico e como 'põem em ação' formas de 'ver' o mundo, identidades, relações, maneiras de construir e distribuir textos, refletindo ideologias e formas de poder. Considerando tais perspectivas, pesquisadores / as, professores / as e alunos / as podem perguntar, por exemplo: que gêneros textuais precedem e / ou seguem os gêneros associados ao que Foucault chama de exame: 'exame médico, exame educacional e muitas variedades de entrevista' (FAIRCLOUGH, 1992, p. 80). Ou ainda, que textos precedem e / ou seguem os gêneros associados ao que Foucault chama de confissão: 'confissão religiosa, discursos terapêuticos e variedades de aconselhamento' (Ibid.), incluindo correio sentimental, conversa entre amigos ou familiares para relatar, desabafar e outras tantas formas de interação humana.

Incorporando princípios e métodos desenvolvidos na ACD, pesquisadores/ as, professores / as e alunos / as terão bases bastante sólidas para ultrapassar 
preocupações com sequências e outros elementos linguístico-textuais que compóem um determinado gênero textual, examinando-o também como prática discursiva e prática social, com as múltiplas implicações das perspectivas teóricas e metodológicas abordadas [no meu] capítulo [de 2005] e melhor elaboradas nos trabalhos de Fairclough. (MEURER, 2005, p.106)."

\section{Referências}

MEURER, J.L. Uma dimensão crítica do estudo de gêneros textuais. In: MEURER, J.L.; MOTTA-ROTH, D. (Org.). Gêneros textuais e práticas discursivas: subsídios para o ensino da linguagem. Bauru: EDUSC, 2003, p.17-29.

MEURER, J.L. Gêneros textuais na análise crítica de Fairclough. In: MEURER, J.L.; BONINI, A.; MOTTA-ROTH, D. (Org.). Gêneros: teorias, métodos e debates. São Paulo: Parábola Editorial, 2005, p.81-106.

Anna Elizabeth Balocco pergunta: Complementando a pergunta anterior apresentada pela colega Desiree da Motta Roth, existe uma "utopia" implícita no seu projeto de pesquisa?

\section{Professor José Luiz Meurer responde:}

"O mundo é, em alguns contextos, caracterizado por estruturas perversas. Princípios sociológicos como aqueles que discuti neste trabalho podem contribuir para uma compreensão mais clara sobre quais estruturas de significação são legitimadas para o beneficio ou vantagem de que formas de alocação e autorização. MINHA UTOPIA é que as teorizações e métodos de análise de práticas discursivas desenvolvidos na LSF e na ACD possam ser expandidos e venham a ter resultados positivos derivados da compreensão dos indivíduos a respeito dessas estruturas. Essas teorizações e métodos podem auxiliar a perceber relações de causa e consequência entre a linguagem e o contexto da cultura, levando à reflexão sociologicamente fundamentada sobre identidades, sobre significações e formas de dominação. Isso pode legitimamente auxiliar na condução de 'políticas de vida' (GIDDENS, 1991, p. 209-233) mais democráticas nos contextos imediatos e nos intercontextos mais amplos das práticas humanas. A linguagem é a 'arma'.”

Referência

CALDAS-COULTHARD, C. R.; FIGUEIREDO, D. C. (Org.). Linguagem em Discurso, v. 4, numero especial 2004, p. 152-153. 
Carla Reichman pergunta: Nos anos noventa, alinhando-se a Fairclough (1989, 1992), Giddens (1979, 1991) e Kress (1989), seu trabalho como orientador já sinalizava claramente sua preocupação com construções identitárias, uma questão contemporânea que perpassa e mobiliza todo o campo das Ciências Humanas e Sociais. Pensando nesses termos, como também na questão que o Sr. colocou sobre a linguagem como 'arma', ou ainda, como ferramenta de trabalho do profissional de lingua(gem) - como que o Sr. vê a construção da nossa própria narrativa?

\section{Professor José Luiz Meurer responde:}

"Novos estudos sobre diferentes gêneros textuais precisam desenvolver instrumentos teóricos e práticos para demonstrar com clareza e de maneira fácil de se perceber que, através de textos orais e escritos, as pessoas criam representaçóes que refletem, constroem e / ou desafiam conhecimentos e crenças, e cooperam para o estabelecimento de relaçóes sociais e identidades. A construção diária da nossa própria narrativa pessoal como ser humano é em grande parte determinada pelos textos que produzimos e a que estamos expostos. Semelhantemente ao que vimos ocorrer na narrativa pessoal discutida neste trabalho, as representaçôes que construímos do mundo, da 'realidade' que nos cerca, muitas vezes refletem e reconstróem uma visão naturalizada, não problematizada dessa realidade. Entretanto, nada é estável e fixo, e novas formas de perceber e expressar discursivamente podem, e muitas vezes deveriam, levar à construção de novas 'realidades”.

\section{Referência}

MEURER, J. L. O trabalho de leitura crítica: recompondo representações, relaçōes e identidades sociais. Ilha do Desterro, v.1, n.38, 168-169, 2000.

Gisele de Carvalho pergunta: Quem trabalha com discurso parece nunca estar imune à reflexão sobre seu objeto de estudo. Quem trabalha com discurso e, mais ainda, é professor parece ser tomado de uma certa "deformação profissional" e, mesmo nos momentos de lazer, se encontra pensando em suas aulas, nos conceitos com que trabalha e como poderia fazer com que eles se tornem mais facilmente compreendidos por seus alunos. Se essa situação lhe parece familiar, o Sr. poderia relatar uma ocasião em que um evento pouco ou nada acadêmico serviu para ilustrar um conceito? 
Professor José Luiz Meurer responde:

"Como a noção de poder criativo ou constitutivo do discurso é central à ACD. Vou dar um exemplo, embora bastante simples, numa tentativa de tornar essa noção mais visível para leitores menos habituados a esta área. $\mathrm{O}$ exemplo mostra a criação explícita de uma personalidade em um showcomédia de Jô Soares no Metropolitan (Rio de Janeiro). A criação da personalidade é iniciada por Jô Soares cerca de 10 minutos após o início do show. Jô Soares interrompe o fluxo 'regular' da sua comédia e interage momentaneamente com o público, causando um certo constrangimento hilário nos membros das primeiras filas da platéia. Uma pessoa qualquer da platéia é escolhida e Jô Soares lhe pede para se levantar e dizer seu nome e de onde vem. Flávio Reich, de Porto Alegre. Durante as quase duas horas de show, Jô Soares volta seguidamente a se referir ao nome de Flávio Reich e, desta forma, vai-se externando uma identidade pública desse indivíduo, antes anônimo, da platéia. Ao se referir a Flávio Reich, Jô Soares o faz sempre pronunciando o seu nome completo, incluindo novos detalhes sobre sua identidade, suas relações sociais, sua importância como pessoa que se destaca na multidão. À medida que a comédia se adianta, acumulam-se rápida e inesperadamente detalhes sobre Flávio Reich, alguns picantes e inusitados, com incursões sobre sua intimidade, ora incluindo possíveis intrigas sobre suas preferências sexuais (pessoas dos altos círculos teriam insinuado, por exemplo, que Flávio Reich é gay, porém usando o termo derrogatório 'bicha'). Acumulamse detalhes sobre as amizades de Flavio Reich e sua evidência social; sobre o prestígio angariado por qualquer pessoa pelo mero fato de ser amigo / a de um / a amigo / a ou de um / a parente de Flávio Reich, de ter visto Flávio Reich, ou de ter jantado no mesmo restaurante onde Flávio Reich esteve uma vez; e outras amenidades e peripécias socialmente ligadas a Flávio Reich, uma grande figura em evidência na atualidade brasileira ao final do show. Para completar, ao terminar o show, Jô Soares volta ao palco pela última vez e, em entoação e postura apoteóticas, declara que tem 'a grande honra e emoção de dedicar o show que se encerra a Flávio Reich, naturalmente'. No momento em que escrevo o presente capítulo, cerca de 5 anos após o evento, a criação discursiva da personalidade continua viva em minha memória: um indivíduo anônimo da platéia é transformado em personagem memorável. Apesar de constituir uma brincadeira, a 'invenção' discursiva de Flávio Reich imita ou parodia a criação, recriação ou desafio constantes de muitas outras realidades através do uso de diferentes textos orais e escritos em diferentes contextos do 
mundo contemporâneo. Constituídas discursivamente, muitas dessas realidades passam a ter existência própria, a ser vistas como permanentes, como sendo 'assim mesmo', como naturais. Um dos objetivos da ACD é desconstruir tais naturalizações, buscando evidências de que se fundamentam em ideologias que favorecem interesses ou estruturas sociais específicas."

\section{Referência}

MEURER, J. L. Gêneros textuais na análise crítica de Fairclough. In: MEURER, J. L.; BONINI, A.; MOTTA-ROTH, D. (Org.). Gêneros: teorias, métodos e debates. São Paulo: Parábola Editorial, 2005. p. 89-90

Adair Bonini pergunta: Processos como narrar, argumentar e expor estão presentes na organização textual e têm recebido diferentes explicações e denominações; por exemplo, Adam chama de "sequência textual" e Marcuschi prefere o termo "tipo de texto". Aderindo a esse debate, você apresenta uma explicação alternativa para o fenômeno e defende a utilização do termo "modalidade retórica". Você poderia nos dizer o que é modalidade retórica e como ela se diferencia de gênero textual?

\section{Professor José Luiz Meurer responde:}

"Eu proponho definir gêneros como tipos relativamente estáveis de textos, sejam orais ou escritos, formais ou informais, que podem ser reconhecidos por causa de sua estrutura retórica e função, isto é, sua organização e finalidade. É importante ressaltar que os gêneros não são caracterizados apenas por um conjunto fixo de componentes semióticos denotativos (lingüísticos e visuais) em uma dada organização sequencial, mas por agrupamentos coocorrentes de componentes semióticos denotativos e conotativos utilizados para alcançar certos propósitos em meios sociais reconhecidos. Relacionados a ambientes sociais específicos, os gêneros podem tanto reforçar, reproduzir ou desafiar diferentes relaçôes sociais, identidades e formas de representar a 'realidade'.

A fim de distinguir modalidades retóricas de gêneros, eu proponho que se definam as modalidades retóricas como estratégias textuais semelhantes, que se agrupam diferentemente em diferentes gêneros, e que são utilizadas por escritores e escritoras como meios para textualizar as partes e as funçôes específicas de seus textos. Assim, as modalidades retóricas são padrões reconhecíveis de recursos textuais, os quais estão disponíveis para a produção 
de gêneros específicos. A organização retórica de gêneros específicos é efetivada pelo conjunto de modalidades retóricas que um produtor ou produtora de texto pode utilizar a fim de indicar aos leitores como o seu texto está organizado, qual é relação funcional existente entre as diversas partes do texto e a relação dessas partes com a arquitetura textual como um todo.

Vistos como fenômenos lingüísticos, os gêneros representam a diversidade enquanto as modalidades retóricas representam a unidade; enquanto os gêneros proliferam como formas de prática social, as modalidades retóricas são usadas repetidamente.”

\section{Referências}

MEURER, J. L. Genre as diversity, and rhetorical mode as unity in language use. Ilha do Desterro, Florianópolis, v. 43, n. 2, p. 61-82, 2003.

MEURER, J. L. O conhecimento de gêneros textuais e a formação do profissional da linguagem. In: FORTKAMP, Mailce Borges Mota; TOMITCH, Lêda Maria Braga. (Org.). Aspectos da Lingüistica Aplicada: estudos em homenagem ao Professor Hilário Inácio Bohn. 1. ed. Florianópolis: Insular, 2000. p. 149-166.

Antônia Dilamar pergunta: Que abordagem você utiliza para se ler e analisar criticamente os diferentes gêneros textuais? Quais as vantagens de se usar essa abordagem?

\section{Professor José Luiz Meurer responde:}

"A abordagem que utilizo apóia-se em grande parte na Análise Crítica do Discurso (ACD) e, mais especificamente, na noção de que o discurso tem um poder construtivo tríplice: (1) produz e reproduz conhecimento e crenças por meio de diferentes modos de representar a realidade; (2) estabelece relaçóes sociais; e (3) cria, reforça ou reconstitui identidades (FAIRCLOUGH, 1992). ACD pode ser caracterizada, segundo Heberle (2000, p. 290-1), como:

Uma área multidisciplinar de estudos da linguagem, voltada para a investigação de fenômenos discursivos diversos, principalmente aqueles ligados a problemas de injustiça e opressão, a desigualdades étnicas, socioeconômicas, políticas e / ou culturais. ACD representa, pois, uma alternativa de análise do discurso (van DIJK, 1993), voltada para a conscientização de como a linguagem é utilizada para reforçar desigualdades sociais e para a análise de mudanças em organizações sociais (FAIRCLOUGH, 1995a). 
Em estudos de ACD, há a preocupação com a desconstrução ideológica dos textos, com as relações complexas entre texto, cognição social, poder, sociedade e cultura (van DIJK, 1993; FAIRCLOUGH, 1995a). Consideram-se aspectos sócio-culturais vão além de estudos tradicionais de descrição e explicação de elementos linguísticos mostrando como o discurso reforça e ao mesmo tempo é reforçado pelo status quo, pela estrutura social.

Assim descrever e explicar gêneros textuais relativamente às representações, relações sociais e identidades neles embutidas poderá servir para evidenciar que, no discurso, e através dele, os indivíduos produzem, reproduzem, ou desafiam as estruturas e as práticas sociais onde se inserem. Uma abordagem crítica dessa natureza poderá ajudar a entender que representar o mundo de uma determinada maneira, construir e interpretar textos evidenciando determinadas relações e identidades constituem formas de ideologia. E uma abordagem dessa natureza poderá ajudar a perceber que "a ideologia é mais efetiva quando sua ação é menos visível” (FAIRCLOUGH, 1989, p. 85), quando representaçôes, relaçôes e identidades são vistas como senso comum, naturais e inquestionáveis."

\section{Referência}

MEURER, José Luiz. Uma dimensão crítica do estudo de gêneros textuais.In: MEURER, J. L; MOTTA-ROTH, D. (Org.). Gêneros textuais e práticas discursivas: subsídios para o ensino da linguagem. Bauru, SP: EDUSC, 2002. p. 17-29.

Lêda Maria Braga Tomitch pergunta: A sua tese de doutorado intitulada "Reading Comprehension in L1 and L2: Exploring Text Structure, Schemata, and Advance Organizers" (1985) investiga aspectos cognitivos da leitura ao verificar o efeito dos organizadores antecipatórios na compreensão leitora, tendo como respaldo teórico a teoria dos esquemas, mas já mostra uma preocupação sua com o texto ao explorar também a estrutura retórica no processo de leitura. Sua pesquisa gradativamente voltou-se mais para os textos escritos e para o contexto de sua produção, mas sua preocupação com a leitura pode ser vista em vários de seus textos e também nas citações de seus trabalhos em textos de colegas da área de leitura. Um dos grandes desafios para professores de L1 e L2, e profissionais da educação em geral, é como desenvolver a leitura crítica, para que nossos alunos possam exercer com mais 
propriedade sua cidadania no mundo atual, onde somos cercados por informações por todos os lados. O que o seu trabalho tem a dizer sobre a leitura crítica?

\section{Professor José Luiz Meurer responde:}

"Ler criticamente significa procurar entender que representar o mundo de uma determinada maneira, construir e interpretar textos evidenciando determinadas relaçóes e identidades constituem formas de ideologia. E, como observa Fairclough (1989, p. 85), 'a ideologia é mais efetiva quando sua ação é menos visível', quando as coisas são vistas como senso comum, naturais, não problemáticas. A ideologia perpassa nossas práticas discursivas e sociais e está implícita nas formas de ver, pensar, compreender, recriar ou desafiar e mudar maneiras de falar e agir. Assim, como também afirma Fairclough (p. 85), se alguém se torna consciente de que um determinado aspecto do senso comum, daquilo que parece natural, sustenta desigualdades de poder em detrimento de si próprio ou de si própria, 'aquele aspecto deixa de ser senso comum e pode perder a potencialidade de sustentar desigualdades de poder, isto é, de funcionar ideologicamente.' A leitura tem o potencial de ser um excelente caminho nessa direção.

Uma necessidade e um desafio que permanecem para lingüistas aplicados, psicólogos da cognição e todos os interessados na importância da linguagem para as práticas sociais humanas é a busca de formas de desenvolver a leitura crítica. É preciso ver o processo de leitura não apenas em sua dimensão cognitiva, mas também em sua abrangência social. Nesse contexto, permanece e é premente a necessidade de desenvolver e testar formas de incentivar alunos e professores, e indivíduos em geral, a se interessarem em quebrar o círculo do senso comum, daquilo que parece natural, não problemático, mas que recria e reforça formas de desigualdade e discriminação."

\section{Referências}

MEURER, J. L. Reading Comprehension in L1 and L2: Exploring Text Structure, Schemata, and Advance Organizers. 1985. Tese (Doutorado) - Georgetown University, Washington, DC. Disponível em: UMI (P.O. Box 1764, Ann Arbor, Michigan, USA). (Order No DA8613943), 1985. 236p.

MEURER, J. L. O Trabalho de Leitura Crítica: recompondo representações, relaçóes e identidades sociais. Ilha do Desterro, n. 38, p. 155-173, 2000. 
Vera Menezes pergunta: Você surpreendeu a academia ao escrever um livro sobre aspectos da linguagem da literatura de autoajuda. Ninguém mais teve essa ousadia. O que o motivou a investir nesse estudo?

\section{Professor José Luiz Meurer responde:}

"Bem, uma das características da sociedade contemporânea é a reflexão. As pessoas estão preocupadas com sua auto-identidade, querem se conhecer mais e refletir sobre sua existência. Além disso, existe uma necessidade de confessar, de falar sobre seus problemas, desejos e ideias. Devido à complexidade da vida moderna, as pessoas buscam o aconselhamento, fazem consultas legais, buscam terapias e leitura de livros de auto-ajuda. Ao selecionar um livro de auto-ajuda - Calm down: how to cope with frustration and anger, escrito por Dr. Paul Hauck em 1974 e na oitava impressão em 1993 - para analisar, eu o fiz devido a sua representatividade como uma amostra desse tipo de literatura, um tipo de cultura de massa contemporânea muito lido pelo público em geral, mas amplamente ignorado na análise do discurso. A auto-ajuda constitui uma forma de cultura popular e considero interessante estudar esse tipo de texto para ver como ele é caracterizado como um mecanismo, retoricamente organizado, de interação e argumentação sociais, ou seja, como um modo de ação. Minha intenção não foi avaliar a qualidade do livro, mas estudar esse produto cultural como texto e como prática social.”

\section{Referência}

MEURER, José Luiz. Aspects of Language in Self-Help Counselling. Florianópolis: Pós-Graduação em Inglês, 1998. (Advanced Research English Series; 4)

Carmen Rosa Caldas-Coulthard: Zé Luiz Meurer e eu começamos nossas vidas acadêmicas quando cursamos o primeiro curso de Mestrado em Língua Inglesa da UFSC em 1972. Quando Zé chegou à Florianópolis, era ainda um menino tímido do interior. Desde então, trilhamos nossos caminhos acadêmicos e pessoais juntos. Fizemos doutorado ao mesmo tempo, iniciamos, com Susana Funck, o primeiro curso de Doutorado em Inglês e Literatura Correspondente da UFSC. Trabalhamos juntos por 22 anos e a PGI cresceu conosco e se tornou um centro de excelência em Linguística Aplicada no Brasil, visto o grande número de alunas / os que passaram pelas nossas salas e por nossas vidas. Zé morreu como seu coordenador, ainda batalhando pela causa do ensino construtivo de identidades sadias e comprometidas com o 
social. Tornou-se um grande linguista aplicado, excelente leitor e produtor de textos e admirado professor.

Além de colega, Zé e eu fomos grandes amigos, compartilhando nossos afazeres, nossas alegrias e frustrações de vida.

Ao reler nossa correspondência por e-mail, tento reconstituir nossas múltiplas conversas telefônicas e pessoais e ainda ouço sua voz e gargalhada.

Nossas trocas, muitas vezes divertidas, ainda estão no meu computador. Em muitas de minhas chegadas à Florianópolis, imediatamente me comunicava com Zé e Viv e aberturas de conversas deste tipo eram comuns:

$19 / 07 / 2008$

- Oi, Zezão, estamos de volta na terra.Vamos nos encontrar logo?

- aih carmem e malcolm!

Vamos nos encontrar no Empório (um dos bares de Florianopolis onde sempre nos encontrávamos) para botar as fofocas em dia....

Quando da morte, também precoce de John Sinclair, Zé nos escreve:

$15 / 02 / 2007$

- oi, carmen e Malcolm.

muitissimo obrigado. Estou chorando aqui, pois o John sempre foi muito querido comigo e com a Vivi enquanto estivemos em B'ham, com convite para jantar especial na casa dele e para eu tomar café TODO DIA no office dele (o meu era no lado, no mules!)

e la nave va.

Beijo, zé

Num de seus últimos e-mails para mim, Zé escreve:

$20 / 07 / 2009$

- valeu, Carmen

nois eh f...!!! Zé

Hoje, cinco meses depois de sua morte, eu também devo dizer, valeu Zé. Valeu tua vida vivida com alegria, energia positiva, amizade e companherismo. Valeu todo o teu crescimento como ser humano tentando, por tuas práticas tanto linguísticas como pessoais, contribuir para um mundo melhor. Valeu a tua curta passagem por aqui. La nave va, sim, mas deixas muitas saudades e tua essência sem dúvida permanecerá entre nós. (19/10/2010). 